\title{
Environmental Significance of Perchlorate in Aqueous Systems and its Removal Technologies
}

\author{
Atreyi Ghosh
}

Assistant Professor, Department of Microbiology and Biotechnology, Sister Nivedita University, Kolkata, India

Received: 07 Dec 2021; Received in revised form: 22 Jan 2022; Accepted: 30 Jan 2022; Available online: 08 Feb 2022

C2022 The Author(s). Published by Infogain Publication. This is an open access article under the CC BY license

(https://creativecommons.org/licenses/by/4.0/).

\begin{abstract}
Perchlorate $\left(\mathrm{ClO}_{4}^{-}\right)$is a naturally occurring anion, commonly found in ammonium, potassium, and sodium salts. It is extensively used as an oxidizer in solid rocket propellant, fireworks, batteries and automobile air-bags. Its contamination to environment is generally associated with the release of ammonium perchlorate by defense contractors, military operations and aerospace programs. This anion is very much persistent in the environment due to high activation energy associated with its reduction. At high concentration perchlorate can affect thyroid gland functions, where it is mistakenly taken up in place of iodine. Also, perchlorate has recently been added to the U.S. Environmental Protection Agency's (EPA) drinking water Candidate Contaminant List. It has been found at high concentrations (>1000 $\mathrm{mg} / \mathrm{L}) \mathrm{in}$ surface water and groundwater. Due to the stability in water systems it is difficult to remove by existing physico-chemical techniques such as adsorption, anion exchange and membrane filtration, therefore bioremediation is a promising method to reduce perchlorate from water systems. Biological perchlorate degradation depends on several environmental factors such as presence of nitrate and chlorate, dissolved oxygen, carbon-source and temperature. In this review, environmental occurrence of perchlorate, it's toxicity in various living organism and remediation processes from water environment have been discussed.
\end{abstract}

Keywords-Perchlorate, anion-exchange, rocket propellant, thyroid, drinking water, bioremediation.

\section{INTRODUCTION}

At present, perchlorate contamination is known to be a problem only within the United States. While it appears that drinking water can be satisfactorily treated, current analytical methods cannot reach the detection limits suggested by toxicology studies. In addition, it is not possible to accurately estimate the costs associated with treatment since nearly all work has been conducted on laboratory or pilot scales. Accordingly, issues associated with mass production, implementation, capitalization, and economies of scale are unresolved and preclude a satisfactory cost analysis at this time.The EPA added perchlorate to its Contaminant Candidate List (CCL) for drinking water in 1998 following discoveries of its presence in drinking water supplies throughout the southwestern United States (Dollarhide 1992). The fundamental physical and chemical nature of perchlorate make it difficult to uniquely analyze for and to remediate, especially at the low concentrations typically encountered (i.e., <500 $\mathrm{mg} \mathrm{mL}^{-1}$ ). Although ion chromatography is

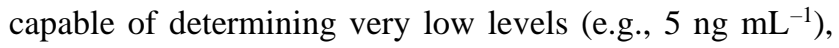
retention time is not considered a unique identifier, and known confirmatory tests have much higher detection limits. Perchlorate ion is unreactive as a ligand and its salts are extremely soluble, even in organic solvents. Despite its strength as an oxidizing agent, perchlorate is nonlabile, that is, very slow to react. While it appears that drinking water can be satisfactorily treated, current analytical methods cannot reach the detection limits suggested by toxicology studies. In addition, it is not possible to accurately estimate the costs associated with treatment since nearly all work has been conducted on laboratory or pilot scales. Accordingly, issues associated 
with mass production, implementation, capitalization, and economies of scale are unresolved and preclude a satisfactory cost analysis at this time. The objective of this review is to provide an overview of the general chemistry, occurrence, toxicology, remediation technologies available for perchlorate.

\section{OCCURRENCE}

Most of the perchlorate contamination has been associated with military activities or defense contractors (Gullic 2001). Ammonium perchlorate is used as a solid oxidant in rocket propulsion. Perchlorate also turns up in fireworks. Perchlorate has been found in groundwater and in surface waters in several western states of U.S., including the Colorado River. Concentrations ranging from $8 \mathrm{ng} \mathrm{mL}^{-1}$ to $3.7 \mathrm{mg} \mathrm{mL}^{-1}$ have been measured from this location. The extensive use of Colorado River water in this region and the proximity of some of these sites to the river have heightened the concern. Perchlorate salts have been found along the Las Vegas Wash. Although additional toxicological studies are ongoing an action level of $18 \mathrm{ng}$ $\mathrm{mL}^{-1}$ has been adopted by California, U.S. Other states have set alternative concentrations, such as Arizona (14 ng $\mathrm{mL}^{-1}$ ) and Texas (22 ng mL $\mathrm{mL}^{-1}$ ). EPA's Regional offices have also set different limits for clean-up of contaminated sites. Low concentrations of perchlorate have been detected sporadically around the U.S., for example, in New York and Iowa. These sites are not associated with any known defense activities, and the source of this perchlorate is not known. It has been speculated that historical use of Chile saltpeter from decades ago may be responsible for some. It is well-known that caliche ore deposits in Chile (which are refined to make sodium nitrate fertilizer) contain natural perchlorate that persists in the final product as a small residue (Ericksen, 1983; Schilt, 1979; Urbansky et al., 2001). Manufacturing changes have further reduced this concentration (currently $=100 \mu \mathrm{g} \mathrm{g}^{-1}$ ) to $5-10 \%$ or less (Lauterbach, 2001). At present, natural saltpeter fertilizers and products derived from them make up less than $0.1 \%$ of the fertilizer applied in the U.S. Data on the historical use of saltpeters is almost nonexistent.

\section{TOXICITY}

The perchlorate ion is similar in size to the iodide ion and can therefore be taken up in place of it by the mammalian thyroid gland. In this way, perchlorate can disrupt the production of thyroid hormones and thus disrupt metabolism. Additionally, other physiological systems may be indirectly affected.
In 1992, the U.S. Environmental Protection Agency (EPA) reviewed and assessed the health effects of perchlorate administered chemotherapeutically to patients with hyperthyroidism (Dollarhide, 1992, 1995 and Stanbury, 1952). This study showed a no observable adverse effects level (NOAEL) of $0.14 \mathrm{mg} \mathrm{kg}^{-1} \mathrm{day}^{-1}$. Doses of $6 \mathrm{mg} \mathrm{kg}^{-1}$ $\mathrm{day}^{-1}$ or more for periods of at least 2 months led to fatal bone marrow changes. The EPA study recommended the following safety/error factors: 10 (nonchronic study), 10 (sensitive persons), 10 or 3 (database error margin) and allowed for two possible uncertainty factors, 1000 and 300. Using the somewhat arbitrary, but relatively accepted, uncertainty factor of 300 , the California DHS established $18 \mathrm{ng} \mathrm{mL}^{-1}$ as the action level for initiating remediation and stopping water usage (Cal DHS, 1997b). This cut-off assumes a $70-\mathrm{kg}$ person consuming $0.5 \mathrm{mg}$ perchlorate for each kilogram body mass who drinks $2 \mathrm{~L}$ of water daily (18 ng mL-1 $\gg .016 \mathrm{mg} \mathrm{mL}^{-1}=0.14 \mathrm{mg} \mathrm{kg}^{-1}$ day-1 ${ }^{\prime} 70$ $\mathrm{kg}$ ' 1 day/2 L , 300). The $0.5 \mathrm{mg}$ number introduces a rounding error that was carried through (Cal DHS,

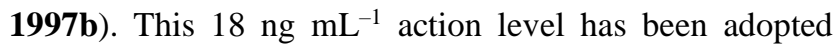
informally by other governmental agencies in the region as well. Using the same assumptions, we would calculate that harmful thyroid effects begin to occur at $49 \mathrm{mg} \mathrm{mL}^{-1}$, and fatalities occur at 210 to $490 \mathrm{mg} \mathrm{mL}^{-1}$. Meanwhile, the European Communities (1982) set a maximum admissible guide level of $20 \mathrm{mg} \mathrm{NaClO} \mathrm{mL}^{-1}$ for drinking water. This corresponds to $16 \mathrm{mg} \mathrm{ClO}_{4}^{-} \mathrm{mL}^{-1}$. Perchlorate exerts its most commonly observed physiological effects on or through the thyroid gland. The primary effect is a decrease in thyroid hormone output. The thyroid gland takes up iodide ion from the bloodstream and converts it to organic iodide in the form of hormones that regulate metabolism. The mechanism responsible for this process, the cellular iodide pump, preferentially selects for anions on the basis of ionic volume: $\mathrm{I}^{-} \gg \mathrm{SCN}^{-}<\mathrm{ClO}_{4}{ }^{-}, \mathrm{TcO}_{4}{ }^{-}$(Chiovato et al., 1997; Cooper, 1991; Foye, 1989 and Orgiassi, 1990). Consequently, the presence of any large anion in the serum reduces thyroid hormone production. This phenomenon was once used pharmaceutically to treat hyperthyroidism, which is known as Graves' disease (Foye, 1989; Chiovato et al., 1997; Cooper, 1991 and Orgiassi, 1990). Chemotherapeutic use of perchlorate was reduced substantially in the United States after several instances of aplastic anemia and renal damage were observed (Foye, 1989 and Hobson, 1961). Domestic perchlorate use is now restricted almost exclusively to use as a diagnostic tool for the evaluation of thyroid hormone production. As a diagnostic tool, perchlorate is still the standard for evaluating thyroid activity; the protocol at the University of California, Los Angeles (UCLA) requires a dose of 0.6 $\mathrm{g}$ (pediatric) or $1 \mathrm{~g}$ (adult) (UCLA, 1997). Although 
perchlorate has been used as a treatment for hyperthyroidism, under the right circumstances it also can act as goitrogen in rodents and prevent thyroid hormone formation by interfering with iodide uptake (Capen and Martin, 1989). The low level of hormone is recognized by the pituitary gland which then stimulates the thyroid gland to work harder, eventually leading to goiter. A recent study of thyroid hormone levels in the Sprague-Dawley rat supported the EPA reference dose of $0.14 \mathrm{mg} \mathrm{kg}^{-1} \mathrm{day}^{-1}$. Male rats exhibited a thyroid NOAEL of $0.44 \mathrm{mg} \mathrm{kg}^{-1}$ day $^{-1}$, but females exhibited a thyroid NOAEL of only $0.124 \mathrm{mg} \mathrm{kg}^{-1}$ day $^{-1}$ (King, 1995). Potassium perchlorate has been used to treat thyrotoxicosis without toxicity at doses ranging from 40 to $120 \mathrm{mg} \mathrm{day}^{-1}$ (Cooper, 1996). If we assume a daily intake of $3 \mathrm{~L}$ of water, this would correspond to 13 to $40 \mathrm{mg} \mathrm{KClO} 4 \mathrm{~mL}^{-1}$, or about 9 to 12 $\mathrm{mg} \mathrm{ClO}_{4}^{-} \mathrm{mL}^{-1}$. This is a factor of about 1000 times the California DHS action level, but close in line with the European Communities level. It is unknown whether secondary effects resulting from decreased thyroid function, indirectly caused by perchlorate, will be consequential.

Perchlorate can directly affect organs and tissues in addition to the thyroid gland. The mouse mammary gland has a mechanism similar to the thyroid iodide pump that is inhibited by perchlorate (Rillema and Rowady, 1997); however, it is unclear whether this has any significance for human health. Much of what is known about perchlorate's effects on living organisms is derived from studies of acute toxicity over relatively short periods of time rather than chronic exposure to very low concentrations over a lifetime.

\section{REMEDIATION AND TREATMENT}

\subsection{Overview}

The best choice for any treatment technology will require a careful evaluation of options and probably some combination of techniques. We must remember that the potential for success of any technology is dependent on two factors: the establishment of a safe level of perchlorate and a quantitative chemical analysis that ensures this safe level is in fact achieved.

\subsection{Remediation by Physical Processes}

Membrane Based Techniques Membrane-based techniques can be effective, but they suffer from several drawbacks. While reverse osmosis (RO) would affect sufficient remediation, it can be impractical for a municipal treatment system because of the fouling of membranes and the associated cost. RO-treated water has to be remineralized with sodium chloride, sodium bicarbonate, and other salts to prevent degradation of the distribution system and to make the water palatable, since deionized water generally is considered to have an unpleasant taste.

\subsection{Anion Exchange Techniques}

Perchlorate ion is strongly retained by quaternary ammonium resins but initially in low concentration in most cases. For example, it might be necessary to reduce perchlorate concentration from $1 \mathrm{mg} \mathrm{mL}^{-1}$ to $20 \mathrm{ng} \mathrm{mL}^{-1}$. Assuming that a chloride-form resin is used, the presence of phosphates, carbonates, and sulfate remains an issue. Although it may be possible to produce a resin salt that matches the proportions of the major anions in the influent water, to do so would be extremely inconvenient. In addition, the low concentration of perchlorate in the raw water substantially reduces the driving force for its removal. In other words, to adequately remove the perchlorate may require essentially demineralizing and remineralizing the water, depending on its anion content. It is possible to modify resins so as to improve their selectivity for particular anions. Kawasaki et al. (1993) have used Dowex $1 \mathrm{X}-8$ to selectively preconcentrate perchlorate; the selectivity of the resin for perchlorate is about 100 times that for chloride and 10 times that for nitrate.

In addition to cost, all physical separation processes have one major problem of waste disposal. Presumably, the regenerant from ion exchange and the concentrate from RO or electrodialysis would contain perchlorate at concentrations too high to be released into a sewage system. This waste presents a problem in terms of cost and post-treatment needs. Although these techniques take the perchlorate out, they concentrate it somewhere else where it must be dealt with later.

\subsection{Remediation by Chemical and Electrochemical Processes}

Here we refer to reduction specifically in the redox sense of adding electrons. From the previous studies of the oxidation-reduction reactions of perchlorate, it is clear that chemical reduction will play no role in drinking water treatment in the near future. Chemical reduction is simply too slow. Unless safe new atalysts become available, this appears unlikely to change. Commonplace reductants (e.g., iron metal; thiosulfate, sulfite, iodide, and ferrous ions) do not react at any observable rate, and the more reactive species are too toxic (and still too sluggish). In addition, any reductant will necessarily have oxidized by-products. The toxicity of the by-products must be considered. There is more hope for electrochemical reduction. A decided advantage of electrochemical reduction is the large amount of control over kinetics that results from control of the operating potential. Electrode reduction kinetics 
reasonably can be viewed as being limited by three factors: (1) diffusion of the ions to the electrode surface, (2) association with the electrode surface, and (3) activation past the overpotential required to reach the transition state. Although overpotential usually is the greatest barrier, it also is the one that can be dealt with best. Because we are not concerned with other reductions (including reducing water to hydrogen), the only barrier is the limit of a negative potential that is practical and safe to apply. Fortunately, most of the materials in raw water are reducing agents. Although some may be affected by electroreduction, this probably does not present a significant obstacle. To date, this option has not been explored for low-concentration treatment at anything approaching pilot scale. Although electrochemical technologies are well established for other industries (e.g., electroplating of metals, electrolysis of brine), they have not yet found a place in drinking water treatment. In this category, it appears that the most successful strategies for remediating perchlorate contamination will utilize metal cation-catalyzed reduction by either chemical or electrochemical means. Several metal chelates have potential at this point, especially if embedded in an electrode for use in electrochemical reduction.

\subsection{Biological and Biochemical Techniques}

Bioremediation is another matter entirely, and it may prove to be the most practical approach. A number of bacteria that contain nitrate reductases (Payne, 1973) are capable of reducing perchlorate (Schilt, 1979). Staphylococcus epidermidis is capable of reducing perchlorate in the absence of nitrate. Cell-free extracts of nitrate-adapted Bacillus cereus also reduce perchlorate (and chlorate) (Hackenthal, 1965). As would be expected, sodium perchlorate, especially in higher concentrations, has been shown to be toxic to several species of bacteria. Like $S$. epidermidis, B. cereus is also pathogenic. B.cereus is known for food poisoning, ocular infections, and pneumonia with other sites sometimes affected (Tuazon, 1995). Rikken et al. (1996) reported that perchlorate and chlorate are reduced to chloride by Proteobacteria with acetate as a nutrient (reductant) at near-neutral $\mathrm{pH}$. Specifically, they concluded that a dismutase is responsible for all elimination of toxic chlorite from the cell, catalyzing its disproportionation to dioxygen and chloride. However, the uncatalyzed disproportionation of chlorite to chloride and chlorate is not necessarily negligible. Korenkov et al. (1976) patented Vibrio dechloraticans Cuzensove B-1168 for perchlorate reduction; V. dechloraticans is nonsporulating, motile, and gram negative. Malmqvist et al. (1994) showed that Ideonella dechloratans can reduce chlorate, but they did not test for perchlorate reduction. Perchlorate can also be metabolized by Wolinella succinogenes, strain HAP-1 (U.S. Air Force, 1994; Wallace and Attaway, 1994). W. succinogenes is capable of using either chlorate or perchlorate to oxidize Brewer's yeast. Pilot-scale systems at Tyndall AFB, Florida in USA showed that perchlorate levels could be reduced from $3000 \mathrm{mg} \mathrm{mL}^{-1}$ to below 0.5 $\mathrm{mg} \mathrm{mL}^{-1}$ (Hurley et al., 1997). HAP-1 was first isolated from a municipal anaerobic digestor. The bacterium is an antibiotic resistant, nonsporulating, motile, Gram-negative, obligately anaerobic bacillus (Wallace et al., 1996). This sort of remediation may be effective at a site where perchlorate concentrations in water are high, but it would be impractical for the treatment of drinking water unless it can be demonstrated to reach even lower perchlorate concentrations. Very little research has been done on perchlorate reductases. It may be possible to isolate these from bacteria and use them directly as reagents without the parent organisms. The mechanisms of these catalysts are not well understood, and the reductases themselves have not been well characterized. It may be possible to synthesize an analogous catalyst based on the reductase, but only if the fundamental bioinorganic chemistry is understood. Although nitrate reductases are based on molybdenum (Coughlan, 1980), it has not been verified whether this is also true for the perchlorate reductases. Several projects are ongoing in the affected areas of EPA (Environmental Protection Agency). Catts (1998) reported that a pilot-scale bioreactor has been constructed for the Baldwin Park Operable Unit in California, USA using microbes derived from the food-processing industry. Operation of this pilot unit over a period of several months showed that perchlorate and nitrate could be reduced to undetectable levels, i.e., $\left[\mathrm{ClO}_{4}^{-}\right]<4 \mathrm{ng} \mathrm{mL}^{-1}$. Ethanol was used as a food source and minerals were added to the system. The perchlorate-reducing microbes were not isolated or characterized.

\section{CONCLUSION}

Bioremediation appear to be the most economically feasible, fastest, and easiest means of dealing with perchlorate laden waters at all concentrations. Although other techniques may find application to select systems, e.g., point-of-use or small utilities, it appears that biological and biochemical approaches will play the greatest role in solving the perchlorate problem. Some situations may require a combination of technologies to best meet unique needs. This is a complex problem, and many of the standard technologies that have dominated the drinking water industry for the past several decades will not work for this contaminant when used in the conventional ways. Many of the possibly effective 
technologies have not been applied to drinking water specifically, and the interplay with other treatment technologies required for regulation must be assessed. In addition to rapid implementation of effective and workable technologies, ongoing development will be required to find new technologies and to make them affordable into the industry.

\section{REFERENCES}

[1] California Department of Health Services. 1997b. Determination of Perchlorate by Ion Chromatography, Rev. 0. June 3. Sanitation and Radiation Laboratories Branch

[2] Catts J 1998. Biological Treatment of Low Level Perchlorate Contamination. Presented at the Perchlorate Stakeholders Forum, May 19-21, 1998

[3] Chiovato LF, Santini, and Pinchera A. 1997. Treatment of Hyperthyroidism. Pisa, Italy, http://www. thyrolink.com/thyint/2-95int.htm\#intro.

[4] Cooper DS 1996. Treatment of Thyrotoxicosis. In: Braverman LE and. Utiger RD (Eds.), Werner and Ingbar's The Thyroid, 7th ed. Lippincott-Raven, Philadelphia, PA. Ch. 53

[5] Coughlan M Ed 1980. Molybdenum and MolybdenumContaining Enzymes. Pergamon, New York, NY

[6] Dollarhide JS. 1992. Provisional Non-Cancer and Cancer Toxicity Values for Potassium Perchlorate. Memorandum to Dan Stralka, U.S. Environmental Protection Agency

[7] Ericksen GE .1983. The Chilean nitrate deposits. Am Sci 71, 366-374

[8] Foye WO Ed. 1989. Principles of Medicinal Chemistry, 3rd ed. Lea \& Febiger, Philadelphia, PA:612-613

[9] Gullick RW, LeChevallier MW, Barhorst TS 2001. Occurrence of perchlorate in drinking water sources. J Am Water Works Assoc 93 (1) :66-77

[10] Hurley JA, Wallace W and Coppola E. 1997. Prototype Demonstration of Ammonium

[11] Kawasaki MT Omori and Hasegawa K. 1993. Adsorption of pertechnetate on an anion exhange resin. Radiochim. Acta, 63:53-56

[12] King WR Jr. and Garner CS. 1954. Kinetics of the oxidation of vanadium(II) and vanadium(III) ions by perchlorate ion. J. Phys. Chem. 58:29-33

[13] Lauterbach AR.2001. Reduction of perchlorate levels of sodium and potassium nitrates derived from natural caliche ore. Abstract Paper - Am Chem Soc Natl Meet, 222nd, AGRO-47

[14] Malmqvist A T, Welander E, Moore A, Ternström G, Molin and Stenström IM. 1994. Sys. Appl. Microbiol. 17:58-64

[15] Orgiassi J and Mornex R. 1990.Hyperthyroidism. In: M.A. Greer (Ed.), The Thyroid Gland. Raven Press, NewYork, NY: $405-495$

[16] Payne WJ 1973. Bacteriol. Rev. 37:409-452

[17] Perchlorate

Biodegradation.http://www.afcesa.af.mil/afcesa/ce-

magazinefal-story21-htm, Demonstration of Ammonium
Perchlorate

Degradation.

http://www.brooks.af.mil/hsc/al/eq/prod13.html,

Ammonium Perchlorate Biodegradation for Industrial Wastewater Treatment. http://estcp. services.com/projects/comply/comp_a1.htm

[18] Rikken GB, Kroon AGM, and. van Ginkel CG 1996. "Transformation of (per)chlorate into chloride by a newly isolated bacterium: reduction and dismutation." Appl.

[19] Microbiol. Biotechnol., 45:420-426

[20] Rillema JA and Rowady DL. 1997. Proc. Soc. Exp. Biol.Med., 215:366-369

[21] Schilt AA 1979. Perchloric Acid and Perchlorates. GFS Chemical Company, Columbus, OH. Hackenthal, E. Biochem. Pharm. 14:1314-1324

[22] Stanbury JB and Wyngaarden JB. 1952. Effect of perchlorate on the human thyroid gland Metabolism, 1:533539

[23] Tuazon CU 1995. In: Mandell GL, Bennett JE, and Dolin R (Eds.), Mandell, Douglas, and Bennett's Principles and Practice of Infectious Diseases, 4th ed. Churchill Livinstone, New York, NY. Ch. 187

[24] UCLA, University of California, Los Angeles. Capen CC and. Martin SL 1989. Toxicol. Pathol., 17:266- 293

[25] Urbansky ET, Brown SK, Magnuson ML, Kelty CA.2001.Perchlorate levels in samples of sodium nitrate fertilizer derived from Chilean caliche. Environ Pollut 112, 299-302

[26] U.S. Air Force. 1994. U.S. Patent 5,302,285

[27] US Environmental Protection Agency (1998): Drinking Water Contaminant Candidate List. Washington, DC, Doc No EPA/600/F-98/002

[28] Wallace W and Attaway H. 1994. Abstr. Gen. Meet. Am. Soc. Microbiol. 421 